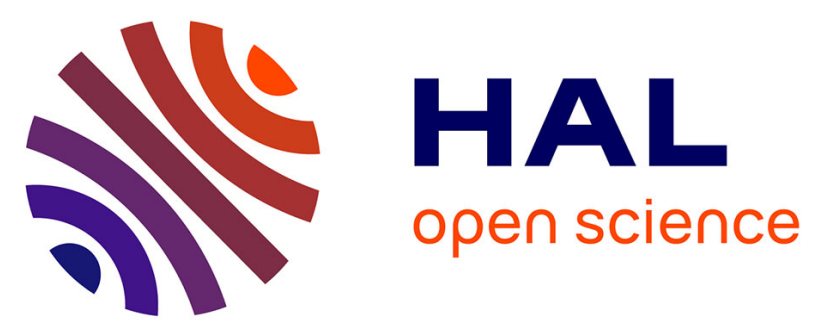

\title{
Effect of metal cation complexation on the nonlinear optical response of an electroactive bisiminopyridine ligand
}

Konstantinos Iliopoulos, Imen Guezguez, Ariadni P. Kerasidou, Abdelkrim El-Ghayoury, Diana-G. Branzea, Gabriela Nita, Narcis Avarvari, Hafed

Belmabrouk, S. Couris, Bouchta Sahraoui

\section{To cite this version:}

Konstantinos Iliopoulos, Imen Guezguez, Ariadni P. Kerasidou, Abdelkrim El-Ghayoury, DianaG. Branzea, et al.. Effect of metal cation complexation on the nonlinear optical response of an electroactive bisiminopyridine ligand. Dyes and Pigments, 2014, 101, pp.229 - 233. 10.1016/j.dyepig.2013.10.006 . hal-03347285

\section{HAL Id: hal-03347285 \\ https://univ-angers.hal.science/hal-03347285}

Submitted on 17 Sep 2021

HAL is a multi-disciplinary open access archive for the deposit and dissemination of scientific research documents, whether they are published or not. The documents may come from teaching and research institutions in France or abroad, or from public or private research centers.
L'archive ouverte pluridisciplinaire HAL, est destinée au dépôt et à la diffusion de documents scientifiques de niveau recherche, publiés ou non, émanant des établissements d'enseignement et de recherche français ou étrangers, des laboratoires publics ou privés. 


\title{
Effect of metal cation complexation on the nonlinear optical response of an electroactive bisiminopyridine ligand
}

\author{
K. Iliopoulos ${ }^{\text {a,b,**, I. Guezguez }}{ }^{\text {a, c }}$, A.P. Kerasidou ${ }^{a}$, A. El-Ghayoury ${ }^{a}$, D. Branzea ${ }^{\text {a }}$, G. Nita ${ }^{\text {a }}$, \\ N. Avarvari ${ }^{a}$, H. Belmabrouk ${ }^{a}$, S. Couris ${ }^{\text {b,d }}$, B. Sahraoui ${ }^{a, *}$ \\ ${ }^{a}$ LUNAM Université, Université d'Angers, CNRS UMR 6200, Laboratoire MOLTECH-Anjou, 2 Bd Lavoisier, 49045 Angers Cedex, France \\ ${ }^{\mathrm{b}}$ Institute of Chemical Engineering Sciences, Foundation for Research and Technology Hellas (FORTH/ICE-HT), 26504 Patras, Greece \\ ${ }^{\mathrm{c}}$ Laboratory Electronic and Microelectronic, University of Monastir, Tunisia \\ ${ }^{\mathrm{d}}$ Department of Physics, University of Patras, Rio, 26504 Patras, Greece
}

\section{A R T I C L E I N F O}

\section{Article history:}

Received 18 July 2013

Received in revised form

30 September 2013

Accepted 1 October 2013

Available online 11 October 2013

\section{Keywords:}

Metal cation complexation

Z-scan

Nonlinear optical response

TTF-ligands

Electronic absorption

Charge transfer

\begin{abstract}
A B S T R A C T
We report on the third order nonlinearities of a bis-iminopyridine-tetrathiafulvalene appended ligand and of its corresponding zinc metal complex. The measurements have been carried out using the Z-scan technique employing $30 \mathrm{ps}, 532 \mathrm{~nm}$ laser excitation. The nonlinear optical response of the zinc complex has been found to be significantly enhanced with respect to the ligand. We illustrate the possibility to control the nonlinear optical response of this electroactive bisiminopyridine ligand. Moreover the obtained results are discussed and compared with previous findings reported in the literature.
\end{abstract}

(c) 2013 Elsevier Ltd. All rights reserved.

\section{Introduction}

Recently, there has been intense interest concerning the investigation of organic materials exhibiting sizeable optical nonlinearities in order to be employed in various opto-electronic and photonic applications [1-6]. Tetrathiafulvalene (TTF)-based materials are of great interest because of their low-first oxidation potential and their unusual stability and solid state properties of the radical cations resulting from the one-electron oxidation of their parent molecules [7]. They have been widely used as the $\pi$-donor components in the preparation of molecular conductors and superconductors $[8,9]$. In addition, they have also found use as redox switches in molecular and supramolecular architectures [10-12]. An active ongoing research theme is the covalent linking of the electroactive TTF unit with a coordinating group in order to produce multifunctional materials which can exhibit interplay between two or more physical properties such as magnetism and conductivity [13-15]. Pyridine based Schiff bases ligands such as

\footnotetext{
* Corresponding author. Tel.: +332 41735489.

** Corresponding author. LUNAM Université, Université d'Angers, CNRS UMR 6200, Laboratoire MOLTECH-Anjou, 2 Bd Lavoisier, 49045 Angers Cedex, France. Tel.: +33 241735423 .

E-mail addresses: kostiliopoulos@gmail.com (K. Iliopoulos), bouchta.sahraoui@ univ-angers.fr (B. Sahraoui).
}

the chelating 2,6-bis(imino)pyridyl unit are well known to form stable complexes, with various transition metals, that have been extensively used as catalysts for olefin polymerization $[16,17]$.

Recently we have demonstrated that the nature of the metal cations plays an important role in the nonlinear absorption of orthogonal TTF-based units where an increase of the nonlinearity was observed in the case of platinum as compared with palladium [18]. Moreover, in the case of TTF-based iron and ruthenium metal complexes we have shown that the incorporation of metal cations results in switching of the character of the nonlinear absorption of the systems from Saturable Absorptive (SA) to Reverse Saturable Absorptive (RSA) [19].

As a continuation of our work, we report herein on the nonlinearity of a TTF-based bisiminopyridine ligand $\mathbf{1}$ and its corresponding zinc complex $\mathbf{2}$ (Scheme 1) [20]. The objective of this work is to find out the impact of the complexation of the ligand by introducing a metal cation on the nonlinear optical response.

\section{Experimental}

\subsection{Z-scan technique}

For the determination of the third order nonlinear optical properties of the systems 1, 2 the well-known Z-scan technique has been 


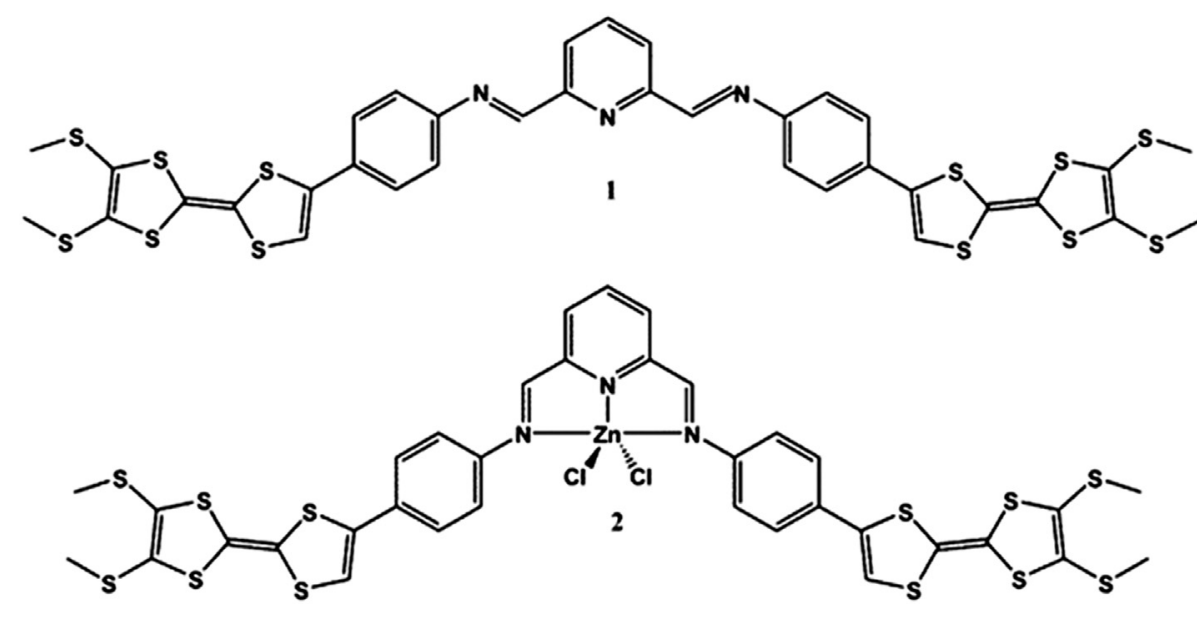

Scheme 1. Chemical structures of ligand $\mathbf{1}$ and zinc complex 2.

utilized [21], employing a 30 ps diode pumped $\mathrm{Nd}: \mathrm{YVO}_{4}$ laser with a repetition rate of $10 \mathrm{~Hz}$. The Z-scan setup will not be presented in detail here as the information can be found in the literature [21,22]. This setup is widely used for the determination of the nonlinearities as it allows the investigation of the magnitude of the nonlinear absorption and refraction of a material, as well as their sign. It is based on measuring the transmittance of a focused laser beam through the sample as it moves along the transmission axis. The transmittance is measured in two different ways, which take place simultaneously. The "open aperture" Z-scan includes detection of the totality of the laser beam after the sample, while concerning the "closed aperture" Z-scan, only the part of the beam which passes through a narrow aperture is detected. By the former the imaginary part of the third order nonlinear susceptibility $\left(\operatorname{Im} \chi^{(3)}\right)$ related to the nonlinear absorption can be determined. The latter includes the contribution of both the nonlinear refraction and absorption to the nonlinearity. Under certain limitations the division of the "closed aperture" by the "open aperture" Z-scan traces (called "divided" Z-scan) can provide the real part of the third order nonlinear susceptibility $\left(\operatorname{Re} \chi^{(3)}\right)$, which is related to the nonlinear refraction of the investigated system. In the case of the nonlinear absorption a minimum or maximum of the transmittance around the focal point corresponds to positive (Reverse Saturable Absorption (RSA)) or negative (Saturable Absorption (SA)) response. In the case of the nonlinear refraction a "valley-peak" or "peak-valley" configuration correspond to positive (self-focusing) or negative (self-defocusing) response.

More specifically from the "open aperture" Z-scan the nonlinear absorption coefficient $(\beta)$ can be obtained by fitting the experimental data according to the following equation:

$T=\sum_{m=0}^{\infty} \frac{\left[-\beta I_{0} L_{\mathrm{eff}} /\left(1+z^{2} / z_{0}^{2}\right)\right]^{m}}{(m+1)^{3 / 2}}$

where $T$ is the normalized transmittance, $L_{\mathrm{eff}}=\left(1-\exp \left(-\alpha_{0} L\right)\right) / a_{0}$ is the effective thickness of the sample, $\alpha_{0}$ is the linear absorption coefficient at the laser excitation wavelength and $I_{0}$ is the on-axis irradiance at the focus. Additionally from the fitting of the divided Z-scan data by means of the following equation:

$T=1-\frac{4 \Delta \Phi_{0} x}{\left(x^{2}+9\right)\left(x^{2}+1\right)}$

the on-axis nonlinear phase shift at the focus $\Delta \Phi_{0}$ can be obtained. The latter is related with the nonlinear refractive index parameter through the equation $\Delta \Phi_{0}=k I_{0} \gamma^{\prime} L_{\text {eff. }}$ By using the following equations the $\operatorname{Re} \chi^{(3)}$ and $\operatorname{Im} \chi^{(3)}$ can be determined from the nonlinear refractive index parameter and the nonlinear absorption coefficient respectively:

$$
\begin{aligned}
& \operatorname{Re} \chi^{(3)}(\mathrm{esu})=\frac{10^{-6} \mathrm{cn}_{0}^{2}}{480 \pi^{2}} \gamma^{\prime}\left(\mathrm{cm}^{2} \mathrm{~W}^{-1}\right) \\
& \operatorname{Im} \chi^{(3)}(\mathrm{esu})=\frac{10^{-7} c^{2} n_{0}^{2}}{96 \pi^{2} \omega} \beta\left(\mathrm{cm} \mathrm{W}^{-1}\right)
\end{aligned}
$$

where $\mathrm{c}$ is the speed of light in $\mathrm{cm} \mathrm{s}^{-1}$ and $\omega$ is the fundamental frequency in cycles $s^{-1}$. The second order hyperpolarizability $(\gamma)$ can be determined from the third order nonlinear susceptibility $\left(\chi^{(3)}\right)$ using the equation:

$\gamma=\frac{\chi^{(3)}}{N L^{4}}$

where $N$ is the number density and $L$ is the local field correction factor.

\section{Results and discussion}

\subsection{UV-Vis absorption studies}

The electronic absorption spectrum of the ligand (1) was recorded in dichloromethane solution $\left(\sim 2 \times 10^{-5} \mathrm{M}\right.$ at room temperature; black line in Fig. 1). This ligand exhibits two strong electronic absorption bands at 269 and $336 \mathrm{~nm}$, which are assigned to the $\pi \rightarrow \pi^{*}$ absorption bands of the TTF and the phenyl ring respectively. The broad band observed in the visible region at about $433 \mathrm{~nm}$ is characteristic of the intramolecular charge transfer transition (ICT) from the highest occupied molecular orbital in the two TTFs to the lowest unoccupied molecular orbital in the electron-accepting imino-pyridyl unit $[23,24]$ and is responsible for the dark orange-red color of this compound.

In our previous report, we prepared and characterized single crystals of the resulting zinc metal complex 2 [20]. The UV-Vis electronic absorption spectrum of the dissolved crystals is shown in Fig. 1, red line. The complex $\mathbf{2}$ exhibits the same features as the free ligand in the UV region $(<400 \mathrm{~nm})$. In the visible region the ICT transition is red shifted indicating an increase of the electron acceptor behavior of ligand $\mathbf{1}$ upon complexation. In addition, the presence of a new shoulder around $385 \mathrm{~nm}$ which corresponds to a ligand centered (LC, $\pi \rightarrow \pi^{*}$ and $n \rightarrow \pi^{*}$ ) absorption is probably due to conformational change of the ligand after complexation with 


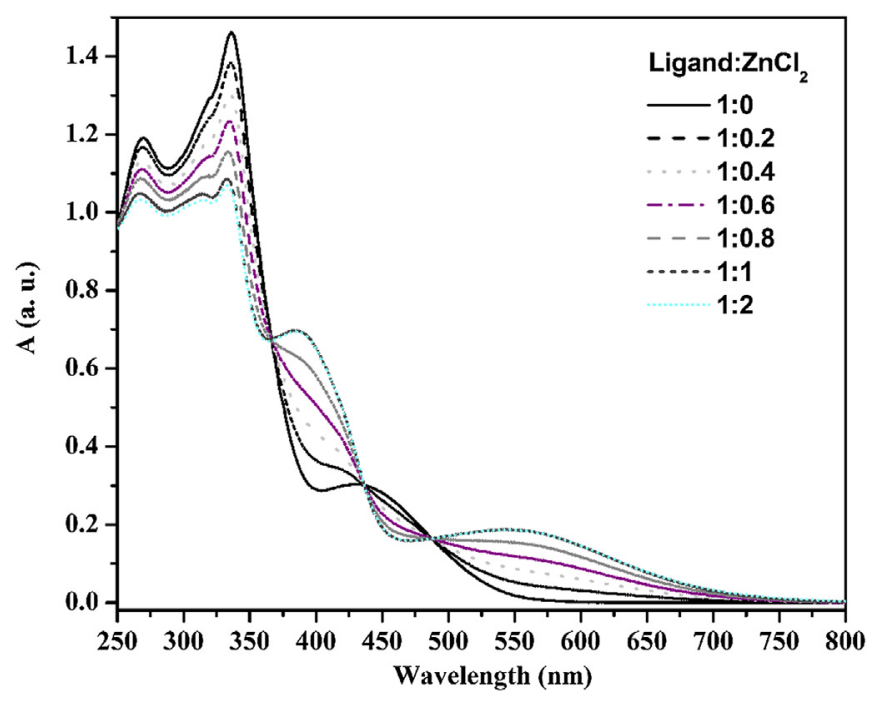

Fig. 1. UV-Vis titration of ligand $\mathbf{1}\left(\mathrm{C}=2.5 \cdot 10^{-5} \mathrm{M}\right)$ by $\mathrm{ZnCl}_{2}$ in a mixture dichloromethane/acetonitrile, $1 / 1$.

zinc chloride. In order to confirm the presence in solution of a single zinc complex specie, UV-Visible electronic absorption titration was performed by adding increasing amounts of a zinc chloride solution into a $\mathrm{CH}_{2} \mathrm{Cl}_{2}$ solution of the ligand $\mathbf{1}$ (Fig. 1 ). These additions result in a decrease of the bands located at 281 and $335 \mathrm{~nm}$ and the appearance of the new band around $385 \mathrm{~nm}$ and a red shift of the ICT band. The presence of three isobestic points at 365,437 and $490 \mathrm{~nm}$ clearly indicates the formation of single zinc complex specie. Note that no additional absorption changes were observed upon introduction of more than one equiv. of $\mathrm{ZnCl}_{2}$, as expected for the formation of the 1:1 complex.

\subsection{Nonlinear optical investigation}

For the characterization of the nonlinear refraction and absorption, the samples have been put in $1 \mathrm{~mm}$ thick quartz cells and studied by means of the Z-scan technique (see experimental section). Several different concentrations ranging from 0.5 to $2 \mathrm{mM}$, in DMF have been prepared for each molecule. For each investigated

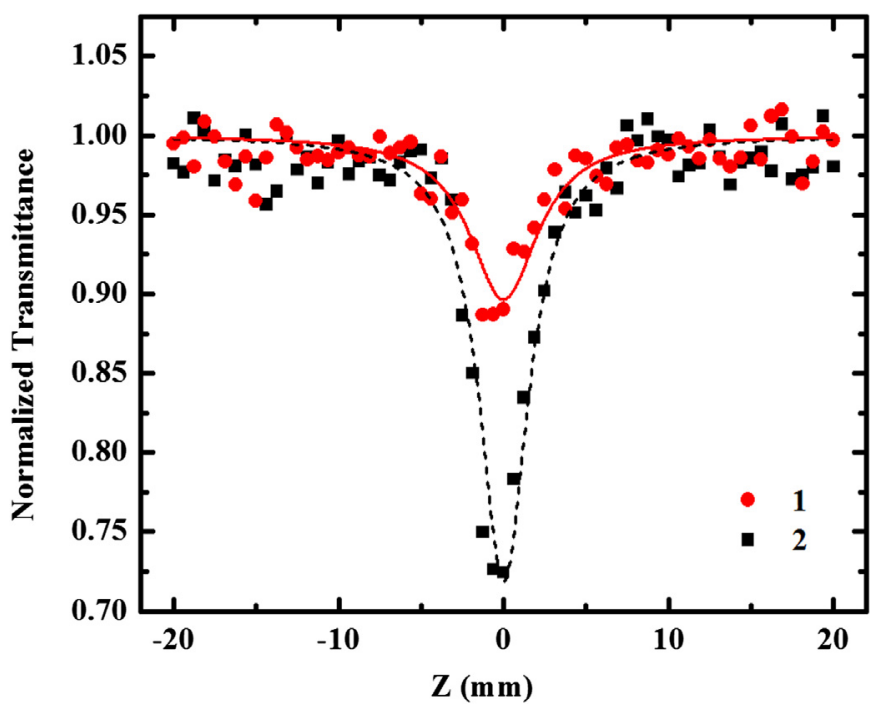

Fig. 2. "Open aperture" Z-scans of the investigated compounds (a) Ligand 1 (b) Zncomplex 2 . concentration, energy-dependent measurements have been carried out. The solvent has been separately investigated showing that its contribution to the nonlinear absorption has been negligible, while the contribution to the nonlinear refraction has been significant under the same experimental conditions.

Concerning the nonlinear absorption of the samples the "open aperture" Z-scans obtained revealed a decrease of the transmittance around the focal point of the lens, which is attributed to Reverse Saturable Absorption (RSA)-type behavior of the sample. In Fig. 2 two characteristic "open aperture" Z-scans are shown corresponding to solutions of the ligand $\mathbf{1}$ and complex $\mathbf{2}$. To facilitate direct comparison both curves, which are shown in Fig. 2 correspond to $1 \mathrm{mM}$ concentration in DMF and were obtained using the same incident laser energy (i.e. $1 \mu \mathrm{J}$ ). It becomes obvious that the nonlinear absorption of the $\mathrm{Zn}$ complex is higher than that of the ligand and this has been verified by a plethora of scans in several different energies and concentrations.

Then, the nonlinear absorption parameter $\beta$ and the corresponding imaginary part of the third order nonlinear susceptibility $\left(\operatorname{Im} \chi^{(3)}\right)$ have been determined from several "open aperture" $\mathrm{Z}$ scans and are presented in Tables 1 and 2. In Fig. 3, the variation of the $\operatorname{Im} \chi^{(3)}$ of both compounds $\mathbf{1}$ and $\mathbf{2}$, as a function of concentration is shown. The large difference between the slopes of the two curves in this graph demonstrates unambiguously the fact that the nonlinear absorption of the Zinc complex $\mathbf{2}$ is much larger than that of the ligand 1. From the slopes shown in Fig. 3 the imaginary part of the second order hyperpolarizability has been determined and is shown in Tables 1 and 2.

However the nonlinear refraction of ligand $\mathbf{1}$ has been found to be negligible as the "closed aperture" and "divided" Z-scans have shown that the only contribution has been emanating from the solvent. For this reason, the second order hyperpolarizability presented in Table 1 in the case of ligand $\mathbf{1}$ is equal to $\operatorname{Im} \gamma$. On the contrary, in the case of the zinc complex $\mathbf{2}$, a nonlinear refractive character of the sample has been found as can be seen in Fig. 4, where two "divided" Z-scans of the solvent and of a of $1.0 \mathrm{mM}$ solution of the zinc complex $\mathbf{2}$ in DMF, under the same experimental conditions (i.e. laser energy of $1.6 \mu \mathrm{J}$ ), are presented. It is clear that the solvent exhibits a positive nonlinear refraction (selffocusing) as the divided Z-scan reveals a "valley-peak" configuration, while in the solution of the complex 2 a "peak-valley" configuration has been found, corresponding to negative nonlinear refraction (self-defocusing). As a result we can deduce that compound $\mathbf{2}$ has a negative nonlinearity, which (at least for the specific laser energy and concentration) is not only canceling the positive contribution of the solvent, but it is also adding up to the selfdefocusing character of the sample, resulting finally to a peakvalley configuration. The magnitude of the $\Delta T_{\mathrm{p}-\mathrm{v}}$ (the difference between the valley and the peak of the divided Z-scan) was dependent upon the concentration and the incident laser energy, and in several cases low or even zero $\Delta T_{\mathrm{p}-\mathrm{v}}$ values have been obtained, which corresponded to cancellation of the two contributions to the nonlinearity. By adjusting the concentration/incident laser energy we have achieved to obtain sufficient signal to noise ratios, as shown as an example in Fig. 4. This behavior clearly

Table 1

Nonlinear optical parameters of the ligand $\mathbf{1}$ (532 nm, 30 ps).

\begin{tabular}{lllc}
\hline Ligand $\mathbf{1}$ & & & \\
\hline Conc. $(\mathrm{mM})$ & $\beta\left(\times 10^{-11} \mathrm{~m} / \mathrm{W}\right)$ & $\operatorname{Im} \chi^{(3)}\left(\times 10^{-13} \mathrm{esu}\right)$ & $\gamma(\operatorname{Im} \gamma)\left(\times 10^{-32} \mathrm{esu}\right)$ \\
\hline 0.5 & 0.18 & 0.10 & 1.25 \\
1.0 & 0.46 & 0.25 & \\
1.5 & 0.66 & 0.36 & \\
2.0 & 1.01 & 0.55 & \\
\hline
\end{tabular}


Table 2

Nonlinear optical parameters of the zinc complex 2 (532 nm, $30 \mathrm{ps})$.

\begin{tabular}{|c|c|c|c|c|c|}
\hline \multicolumn{6}{|c|}{ Zinc complex 2} \\
\hline Conc. (mM) & $\beta\left(\times 10^{-11} \mathrm{~m} / \mathrm{W}\right)$ & $\operatorname{Im} \chi^{(3)}\left(\times 10^{-13}\right.$ esu $)$ & $\operatorname{Im} \gamma\left(\times 10^{-32} \mathrm{esu}\right)$ & $\operatorname{Re} \gamma\left(\times 10^{-32}\right.$ esu $)$ & $\gamma\left(\times 10^{-32}\right.$ esu $)$ \\
\hline 0.50 & 0.80 & 0.44 & 4.50 & -9.30 & 10.24 \\
\hline 0.75 & 1.30 & 0.70 & & & \\
\hline 1.00 & 1.78 & 0.96 & & & \\
\hline 1.50 & 2.36 & 1.28 & & & \\
\hline
\end{tabular}

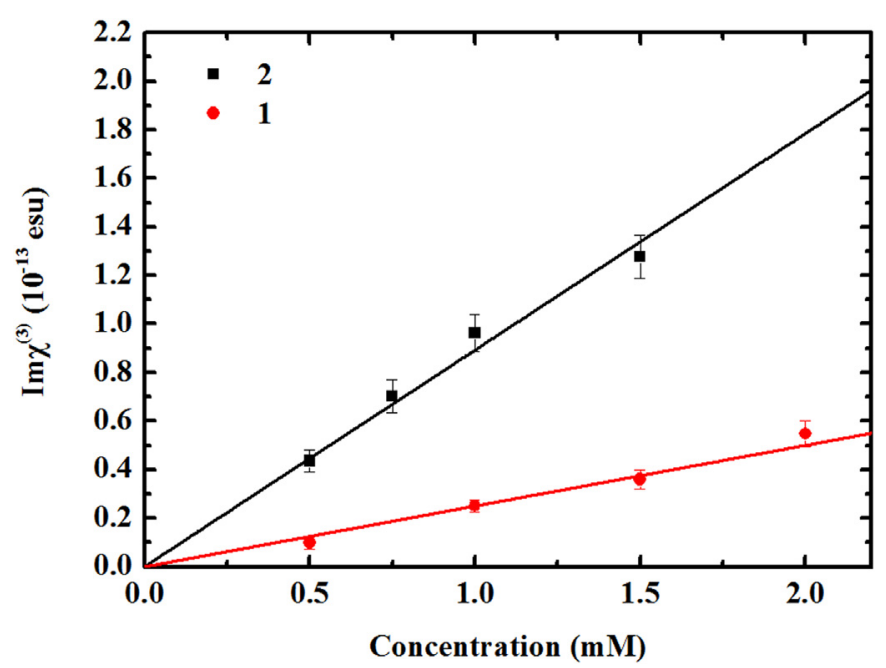

Fig. 3. $\operatorname{Im} \chi^{(3)}$ as a function of concentration for ligand $\mathbf{1}$ and complex $\mathbf{2}$.

indicates a high nonlinear refraction for the zinc complex. The second order hyperpolarizability has been determined for the zinc complex 2 and can be seen in Table 2 .

The nonlinear optical parameters presented in Tables 1 and 2 indicate an increase of the nonlinear absorption of the Zinc complex by about 4 times. This fact combined with the appearance of nonlinear refraction in the case of the complex results to a total increase of the second order hyperpolarizability by about 8 times. This significant enhancement might be explained by the red shift of

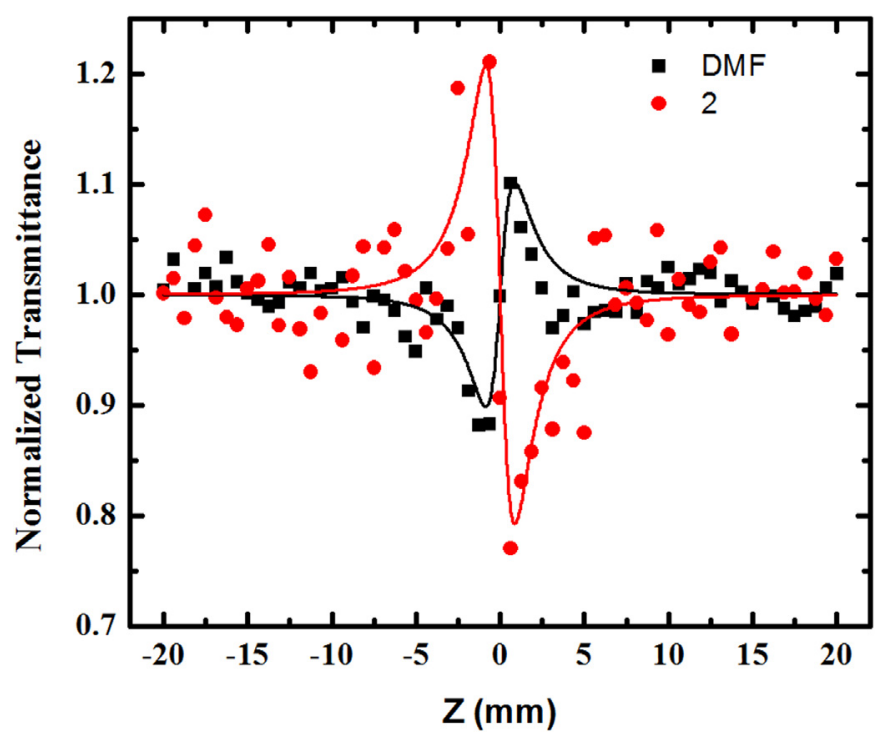

Fig. 4. "Divided" Z-scans obtained for the zinc complex $2(1.0 \mathrm{mM})$ and the solvent (DMF). the intramolecular charge transfer occurring between the TTF unit and bis-iminopyridine fragment upon complexation as clearly shown during the titration of the ligand by adding increasing amount of zinc chloride (Fig. 1).

In a previous publication we have demonstrated [18] that the nonlinear absorption of orthogonal pyrrolo-TTF derivatives is significant if compared with that of the initial ligand, which has been found to be negligible. This result is in agreement with our current findings. Additionally in another recent publication [19] we have shown that the introduction of metal cations can be of great importance as far as the optical nonlinearity of TTF-based systems is concerned. More specifically it has been found that there is a switching of the nonlinear absorption of the molecular systems upon complexation of the ligand with ruthenium or with iron. This behavior has been attributed to the presence of the metal to ligand charge transfer (MLCT) band in the complexes. It is worth noting that in the present case, although no MLCT band is present in complex $\mathbf{2}$, the coordination of metal cation is beneficial for the nonlinear optical response.

\section{Conclusions}

In conclusion, a comparative study of the nonlinear optical response between an electroactive TTF-based ligand and its corresponding zinc complex has been performed. The obtained results demonstrate an enhancement of the nonlinearity upon complexation of the ligand. In this study we have shown the possibility of controlling the nonlinear optical response of these systems by a metal cation complexation. This fact opens new prospects for photonic/opto-electronic applications.

\section{Acknowledgments}

K.I. acknowledges support from the European Commission and General Secretariat for Research and Technology (Greece) for a National Strategic Reference Framework (NSRF) project (PE3(1612)).

\section{References}

[1] El Ouazzani H, Iliopoulos K, Pranaitis M, Krupka O, Smokal V, Kolendo A, et al. Second- and third- order nonlinearities of novel push-pull azobenzene polymers. J Phys Chem B 2011;115:1944-9.

[2] Bouchouit K, Derkowska B, Migalska-Zalas A, Abed S, Benali-cherif N, Sahraoui B. Nonlinear optical properties of selected natural pigments extracted from spinach: carotenoids. Dyes Pigment 2010;86:161-5.

[3] Iliopoulos K, El-Ghayoury A, Derkowska B, Ranganathan A, Batail P, Gindre D et al. Effect of the counter cation on the third order nonlinearity in anionic Au dithiolene complexes. Appl Phys Lett 2012;101. 261105-1-261105-4.

[4] Jiang XF, Polavarapu L, Neo ST, Venkatesan T, Xu QH. Graphene oxides as tunable broadband nonlinear optical materials for femtosecond laser pulses. J Phys Chem Lett 2012;3:785-90.

[5] Papagiannouli I, Iliopoulos K, Gindre D, Sahraoui B, Krupka O, Smokal V, et al Third-order nonlinear optical response of push-pull azobenzene polymers. Chem Phys Lett 2012:554:107-12.

[6] Seniutinas G, Tomašiūnas R, Czaplicki R, Sahraoui B, Daškevičienè M Getautis V, et al. Arylmethylene-1,3-indandione based molecular glasses: third order optical non-linearity. Dyes Pigment 2012;95:33-40. 
[7] Bendikov M, Wudl F, Perepichka DF. Tetrathiafulvalenes, oligoacenenes, and their buckminsterfullerene derivatives: the brick and mortar of organic electronics. Chem Rev 2004;104:4891-945.

[8] Batail P. Introduction: molecular conductors. Chem Rev 2004;104:4887-90.

[9] Bryce MR, Murphy LC. Organic metals. Nature 1984;309:119-26.

[10] Canevet D, Sallé M, Zhang G, Zhang D, Zhu D. Tetrathiafulvalene (TTF) derivatives: key building-blocks for switchable processes. Chem Commun 2009: 2245-69.

[11] Nielsen MB, Lomholt C, Becher J. Tetrathiafulvalenes as building blocks in supramolecular chemistry II. Chem Soc Rev 2000;29:153-64.

[12] Coskun A, Spruell JM, Barin G, Dichtel WR, Flood AH, Botros YY, et al. High hopes: can molecular electronics realise its potential? Chem Soc Rev 2012;41: 4827-59.

[13] Coronado E, Galán-Mascarós JR, Gómez-García CJ, Laukhin V. Coexistence of ferromagnetism and metallic conductivity in a molecule-based layered compound. Nature 2000;408:447-9.

[14] Coronado E, Day P. Magnetic molecular conductors. Chem Rev 2004;104 5419-48

[15] Nihei M, Takahashi N, Nishikawa H, Oshio H. Spin-crossover behavior and electrical conduction property in iron(ii) complexes with tetrathiafulvalene moieties. Dalton Trans 2011;40:2154-6.

[16] Britovsek GJP, Gibson VC, Kimberley BS, Maddox PJ, McTavish SJ, Solan GA et al. Novel olefin polymerization catalysts based on iron and cobalt. Chem Commun 1998:849-50.
[17] Small BL, Brookhart M, Bennett AMA. Highly active iron and cobalt catalysts for the polymerization of ethylene. J Am Chem Soc 1998;120:4049-50.

[18] Iliopoulos K, Czaplicki R, El Ouazzani H, Balandier JY, Chas M, Goeb S, et al, Physical origin of the third order nonlinear optical response of orthogonal pyrrolo-tetrathiafulvalene derivatives. Appl Phys Lett 2010;97. 101104-011101104-3.

[19] Iliopoulos K, El-Ghayoury A, El Ouazzani H, Pranaitis M, Belhadj E, Ripaud E, et al. Nonlinear absorption reversing between an electroactive ligand and its metal complexes. Opt Express 2012;20:25311-6.

[20] Nita G, Branzea D, Pop F, El-Ghayoury A, Avarvari N. Electroactive bisiminopyridine ligands: synthesis and complexation studies. Crystals 2012;2:33848.

[21] Sheik-Bahae M, Said AA, Wei TH, Hagan DJ, Van Stryland EW. Sensitive measurement of optical nonlinearities using a single beam. IEEE J Quantum Electron 1990;26:760-9.

[22] Iliopoulos K, Chatzikyriakos G, Demetriou M, Krasia-Christoforou T, Couris S. Preparation and nonlinear optical response of novel palladium-containing micellar nanohybrids. Opt Mater 2011;33:1342-9.

[23] Chahma M, Hassan N, Alberola A, Stoeckli-Evans H, Pilkington M. Preparation and coordination complex of the first imine-bridged tetrathiafulvalene-pyridine donor ligand. Inorg Chem 2007;46:3807-9.

[24] Andreu R, Malfant I, Lacroix PG, Cassoux P. New tetrathiafulvalene- $\pi$-spaceracceptor derivatives: synthesis, crystal structure, optical and elecochemical properties. Eur J Org Chem 2000;2000:737-41. 